\title{
KINERJA KUALITAS PELAYANAN DAN PENGARUHNYA TERHADAP KEPUASAN PELANGGAN BENGKEL JM MOTOR BANDUNG BARAT
}

\author{
Suharyanto \\ Prodi Teknik Industri, Universitas Kebangsaan \\ e-mail: yanto_sy2008@yahoo.com
}

\begin{abstract}
Abstrak
The motorcycle industry in Indonesia have been growing fast in recent years and it is synergic with the motorcycle demanded by the people. The motor cyles service station increase simultaneously with motorcycle population. The motorcyles service station that exist in Kelurahan Tanimulya, Kecamatan Ngamprah Kabupaten Bandung Barat more than ten units including JM Motor. The impacts and consequencies caused by this condition are: the competitive climate and the owners have to defense, struggle and improve their businesses. These aims can be reached through service quality improvement and customer satisfaction. The JM Motor Service station serves the many kinds and brands of motorcyles such as general check-up, oil refilling, engine tune-up and overhauls, lamps and tires replacement and others including sales of spareparts. This research provides to know the service quality aspects (reliability, responsiveness, assurance, empathy and tangibles) that have been giving and effects to the customer satisfaction. The 40 questionnaires collected by using incidental sampling method to get the service quality and customer satisfaction data and interviews to get the managerial data. The result shows that the services quality aspects effected low rated with coefficient of determination $R^{2}=$ $32,6 \%$; it means that services quality effected to customers satisfaction $32,6 \%$ and $67,4 \%$ caused by other factors. The regression equation constructed is CS $=3.482+0.143 S Q$, where CS $=$ customers satisfaction and $S Q=$ services quality. It means that services quality gives rather low impact to customers satisfaction of JM Motor Service station.
\end{abstract}

Key words : services quality, customers satisfaction, linier regression equation

\section{PENDAHULUAN}

Industri kendaraan bermotor di Indonesia berkembang cukup pesat pada dekade setelah tahun 2000an dengan tingkat pertumbuhan penjualan, reparasi mencapai $4.84 \%$ per tahun (Kemenperin, 2015). Salah satu penyebabnya adalah adanya peningkatan aktivitas masyarakat yang mengakibatkan peningkatan kebutuhan akan mobilitas yang mudah, murah dan handal. Sepeda motor merupakan salah satu moda yang praktis, memiliki mobilitas dan fleksibilitas tinggi serta harga yang terjangkau bagi sebagian besar masyarakat. Pemilik sepeda motor akan selalu berusaha agar kondisi motornya prima baik penampilan luar maupun kinerja mesinnya.

Sektor jasa retail, perbaikan kendaraan dan sepeda motor memberikan kontribusi terhadap PDB Indonesia sebesar 13,27\% pada tahun 2013 dan 13,38\% pada 2014 (Kemenperin, 2015). Sedangkan di Kabupaten Bandung Barat, sektor perdagangan besar dan eceran serta reparasi mobil dan motor memberikan kontribusi 12\% terhadap PDRB (BPS Bandung Barat, 2015). Pertumbuhan banyaknya sepeda motor di Jawa Barat mencapai 17,06\%(BPS Jabar, 2014), dan banyaknya sepeda motor di Kabupaten Bandung Barat pada tahun 2015 mencapai 22.012 unit (BPS Bandung Barat, 2015). Melihat kondisi demikian, usaha reparasi sepeda motor masih menjadi peluang usaha yang cukup menarik dan dan bisa menyerap tenaga kerja. Sejak berdirinya tahun 2013, bengkel JM motor harus bersaing di desa Tanimulya dengan 5 buah bengkel motor lainnya, di samping di desa sebelahnya Cipageran sebanyak 7 buah. Pihak pemilik bengkel berusaha meningkatkan jumlah pelanggan dengan memberikan layanan yang lebih baik dan berusaha memuaskan pelanggannya. Hal ini didasarkan pada catatan komplain pelanggan selama 3 bulan terakhir (Januari-Maret 2017) seperti dalam tabel 1. 
Tabel 1. Banyaknya complain JM Motor

\begin{tabular}{clc}
\hline No & Jenis komplain & Jumlah \\
\hline 1 & Waktu pengerjaan lama & 5 \\
2 & Keluhan kerusakan terjadi lagi & 7 \\
3 & Ongkos servis cukup mahal & 4 \\
4 & Harga sparepart cukup mahal & 2 \\
5 & Diagnosis kerusakan kurang tepat & 5 \\
\hline
\end{tabular}

*) sumber: pemilik bengkel

Pada umumnya, pemilik motor akan membawa motornya ke bengkel dalam kondisi tertentu, baik untuk perawatan rutin (diantaranya ganti oli, busi, kampas rem) atau insidental berupa mati mesin, ban kempes dan sebagainya. Untuk perawatan rutin, terdapat kecenderungan pemilik motor akan memilih bengkel langganannya sedangkan untuk perbaikan insidental akan dibawa ke bengkel terdekat, namun tidak tertutup kemungkinan ke bengkel langganannya juga.

Selama ini pelanggan yang menservis motornya di JM Motor berkisar 5-10 motor per hari pada hari biasa, dan sekitar 10-15 pada hari Sabtu. Pemilik merasakan pelayanan yang telah diberikan sudah baik, namun masih banyak menerima komplain dari pelanggan berupa waktu layanan yang lama karena menunggu atau karena ketiadaan spareparts, serta tempat menunggu yang masih kurang nyaman.

Oleh karena itu manajemen bengkel JM Motor merasa perlu melakukan penelitian untuk mengetahui secara pasti bagaimana pelayanan yang sudah diberikan apakah dapat memuaskan pelanggan atau belum. Diharapkan dengan kualitas pelayanan yang baik dapat meningkatkan kepuasan pelanggan bengkel motor yang pada akhirnya dalam jangka panjang meningkatkan jumlah pelanggan. Oleh karena itu penelitian yang dilakukan mengambil judul: Kinerja Kualitas Pelayanan dan Pengaruhnya terhadap Kepuasan Pelanggan Bengkel JM motor Bandung Barat.

\section{METODE PENELITIAN}

\section{A. Kerangka Pemikiran dan Hipotesis}

Penelitian ini merupakan penelitian deskriptif untuk menggambarkan kondisi tingkat kepuasan pelanggan servis sepeda motor di JM Motor yang diterima dan yang mereka harapkan. Populasi dalam penelitian ini adalah pelanggan servis sepeda motor di JM Motor dan sampel merupakan pelanggan yang terpilih secara acak sederhana (simple random sampling), dan kuesioner disebarkan secara sebanyak 40 buah. Kemudian dilakukan rekapitulasi jawaban dan diuji kecukupan data, uji reliabilitas, validitas instrumen dan dihitung tingkat kualitas pelayanan yang diterima (kinerja) serta tingkat kepuasannya. Hipotesis yang disusun adalah:

Ho: tidak ada pengaruh signifikan kualitas pelayanan terhadap tingkat kepuasan pelanggan servis di JM Motor

H1: ada pengaruh signifikan kualitas pelayanan terhadap tingkat kepuasan pelanggan servis di JM Motor

Untuk mengetahui pengaruh langsung variabel kualitas pelayanan terhadap kepuasan pelanggan dilakukan uji $\mathrm{t}$ dan uji F. Model hubungan kualitas pelayanan dengan kepuasan pelanggan diwujudkan dengan persamaan regresi linier. Kerangka pemikiran ini dapat digambarkan dalam gambar 1. sebagai berikut:

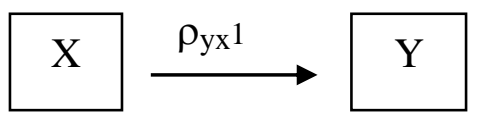

Gambar 1. Skema Kerangka Pemikiran 
Keterangan

$\mathrm{X}$ : variabel bebas, yaitu kualitas pelayanan (dimensi kehandalan (reliability), ketanggapan (responsiveness), empati (empathy), jaminan (assurance), fisik (tangibles)

Y: variabel terikat, yaitu kepuasan pelanggan

Kemudian model regresi linier dilakukan uji asumsi klasik. Bagan alir langkah penelitian ini digambarkan seperti Gambar 3. berikut ini:

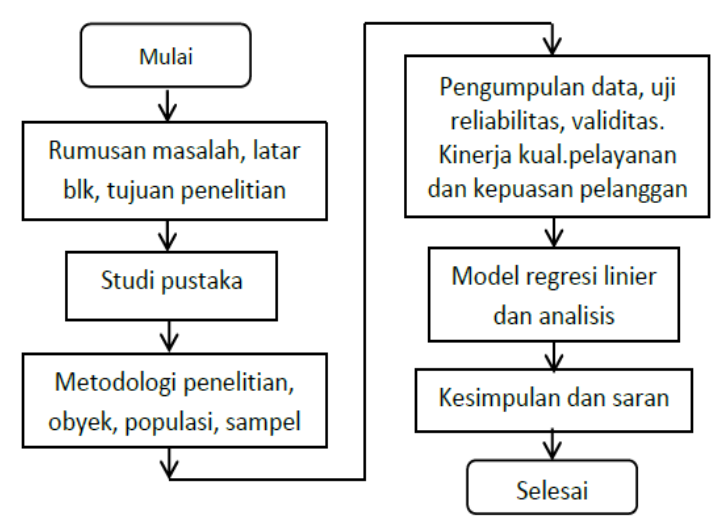

B. Populasi dan Sampel

Gambar 3. Bagan alir penelitian

Dalam penelitian ini, unit penelitian adalah JM Motor Bandung Barat, yang berlokasi di Desa Tanimulya Bandung Barat. Data yang diperlukan diperoleh secara langsung dari responden pelanggan, maupun dari pihak manajemen. Penelitian ini bersifat deskriptif verifikatif. Menurut Malhotra, penelitian deskriptif "a type of conclusive research that has its major objective the descriptive of something, usually characteristics or functions. Menurut Sugiyono (2009), penelitian deskriptif adalah penelitian dengan tujuan utama menggambarkan sesuatu dan biasanya karakteristik atau fungsi. Sedangkan penelitian verifikatif digunakan untuk meneliti hubungan variabel independen berupa kinerja kualitas pelayanan dan variabel dependen berupa kepuasan pelanggan. Populasi ditentukan berupa pelanggan JM Motor, dengan sampel ditentukan dengan memilih secara insidental sebanyak 40 responden pada bulan April 2017.

\section{Operasionalisasi Variabel}

Variabel independen berupa aktivitas terkait dengan lima dimensi kualitas pelayanan menurut Parasuraman (reliabilitas, responsiveness, assurance, empathy dan tangible). Variabel dependen merupakan hasil atau akibat dari adanya/dilakukannya aktivitas pada variabel independen, berupa kepuasan pelanggan JM Motor Bandung Barat. Variabel kualitas pelayanan diuraikan dalam bentuk pertanyaan yang mewakili kelima dimensi kualitas pelayanan, yaitu kehandalan (reliability) (X1), kepekaan (responsiveness) (X2), jaminan (assurance) (X3), empati (empathy) (X4) dan fasilitas yang terlihat (tangible) (X5). Variabel dependen (Y) yaitu berupa kepuasan yang dirasakan oleh pelanggan JM Motor. Semua dimensi kualitas pelayanan diuraikan atas pertanyaan-pertanyaan dengan pilihan jawaban tertutup menggunakan skala ordinal (Likert) dengan 5 pilihan jawaban untuk tingkat kinerja (saat ini) dan tingkat kepentingan (harapan). Skala penilaian maupun operasionalisasi variabel dapat dilihat dalam tabel 1,2 dan 3 . 
Tabel 1. Skala penilaian kinerja

\begin{tabular}{cc}
\hline Skala & Tingkat kinerja \\
\hline 5 & Sangat baik \\
4 & Baik \\
3 & Cukup baik \\
2 & Tidak baik \\
1 & Sangat tidak baik \\
\hline
\end{tabular}

Tabel 2. Skala penilaian harapan

\begin{tabular}{cc}
\hline Skala & Tingkat kinerja \\
\hline 5 & Sangat baik \\
4 & Baik \\
3 & Cukup baik \\
2 & Tidak baik \\
1 & Sangat tidak baik \\
\hline
\end{tabular}

Table 3. Operasionalisasi variabel

Definisi operasional: Kinerja berbagai faktor yang dapat mempengaruhi kepuasan pelanggan atas pelayanan jasa yang diterimanya, terdiri atas kehandalan (reliability), kepekaan (responsiveness), jaminan (assurance), empati (empathy), perangkat yang terlihat (tangible)

\begin{tabular}{|c|c|c|}
\hline $\begin{array}{l}\text { Dimensi } \\
\text { Kualitas } \\
\text { Pelayanan }\end{array}$ & Indikator & Satuan ukuran \\
\hline \multirow[t]{5}{*}{$\begin{array}{r}\text { Kehandalan } \\
\text { (reliability) }\end{array}$} & $\begin{array}{l}\text { 1. Menyelenggarakan layanan servis } \\
\text { motor seperti yang dijanjikan }\end{array}$ & Tingkatan pelayanan \\
\hline & $\begin{array}{l}\text { 2. Ketidaktergantungan kepada pihak } \\
\text { lain dalam menangani servis motor }\end{array}$ & $\begin{array}{c}\text { Tingkatan } \\
\text { ketidaktergantungan }\end{array}$ \\
\hline & $\begin{array}{l}\text { 3. Menghasilkan layanan servis sepeda } \\
\text { motor pertama kali secara tepat }\end{array}$ & Tingkatan pelayanan \\
\hline & $\begin{array}{l}\text { 4. Menyelenggarakan servis motor } \\
\text { sesuai waktu yang dijanjikan }\end{array}$ & Ketepatan waktu \\
\hline & $\begin{array}{l}\text { 5. Memastikan kapan layanan servis } \\
\text { sepeda motor akan diberikan/selesai }\end{array}$ & $\begin{array}{c}\text { Tingkatan kepastian } \\
\text { pelayanan }\end{array}$ \\
\hline \multirow[t]{3}{*}{$\begin{array}{l}\text { Kepekaaan } \\
\text { (responsiveness) }\end{array}$} & $\begin{array}{l}\text { 6. Kecepatan menyampaikan layanan } \\
\text { kpd pelanggan servis motor }\end{array}$ & Tingkatan kecepatan \\
\hline & $\begin{array}{l}\text { 7. Kemauan membantu pelanggan servis } \\
\text { motor }\end{array}$ & Tingkatan kemauan \\
\hline & $\begin{array}{l}\text { 8. Kesiapan menanggapi permintaan/ } \\
\text { keluhan pelanggan }\end{array}$ & $\begin{array}{l}\text { Tingkatan } \\
\text { ketanggapan }\end{array}$ \\
\hline \multirow[t]{4}{*}{$\begin{array}{l}\text { Jaminan } \\
\text { (assurance) }\end{array}$} & $\begin{array}{l}\text { 9. Pimpinan dan karyawan (montir) } \\
\text { menumbuhkan kepercayaan } \\
\text { pelanggan }\end{array}$ & $\begin{array}{l}\text { Tingkatan } \\
\text { kepercayaan }\end{array}$ \\
\hline & $\begin{array}{l}\text { 10. Memastikan pelanggan servis motor } \\
\text { aman dan nyaman pada saat dilayani }\end{array}$ & Tingkatan keamanan \\
\hline & $\begin{array}{l}\text { 11. Pimpinan dan karyawan (montir) } \\
\text { sopan melayani pelanggan }\end{array}$ & $\begin{array}{l}\text { Tingkatan } \\
\text { kesopanan }\end{array}$ \\
\hline & $\begin{array}{l}\text { 12. Pimpinan dan monti memiliki } \\
\text { pengetahuan menjawab pertanyaan } \\
\text { pelanggan }\end{array}$ & $\begin{array}{l}\text { Tingkatan } \\
\text { pengetahuan }\end{array}$ \\
\hline $\begin{array}{l}\text { Empati } \\
\text { (empathy) }\end{array}$ & $\begin{array}{l}\text { 13. Memberikan perhatian kepada } \\
\text { pelanggan servis motor }\end{array}$ & Tingkatan perhatian \\
\hline
\end{tabular}


Fasilitas yang terlihat (tangibles)
14. Pimpinan dan karyawan (montir) memperta-hankan tradisi baik saat menghadapi pelanggan

15. Memberikan daya tarik di hati pelanggan

16. Pimpinan dan karyawan memahami kebutuhan pelanggan servis sepeda motor

17. Peralatan servis yang digunakan dalam kondisi baik dan modern

18. Fasilitas dan tempat menarik secara visual

19. Pimpinan dan montir bekerja profesional

20. Pimpinan dan karyawan (montir) meyakinkan/menarik secara visual

21. Lama waktu pelayanan cepat dan tepat

Kepuasan pelanggan 22. Kenyamanan dalam menerima (Customer Satisfaction) pelayanan yang diterima

23. Penggunaan/pemanfaatan fasilitas servis motor selanjutnya di JM Motor

24. Memberikan masukan untuk perbaikan kepada pimpinan dan karyawan (montir)

25. Rekomendasi kepada orang lain untuk servis motor di JM Motor
Tingkatan tradisi

Tingkatan daya tarik

Tingkatan pemahaman

Tingkatan kondisi modern

Tingkatdaya tarik visual Tingkat profesionalisme Tingkatan daya tarik visual

Tingkatan ketepatan

Tingkatan kenyamann

Tingkatan/ frekuensi penggunaan

Tingkatan/ frekuensi

Tingkatan rekomendasi

\section{HASIL DAN PEMBAHASAN}

\section{A.Uji kecukupan, reliabilitas dan validitas data}

Data yang dikumpulkan berupa jawaban responden atas kinerja kualitas pelayanan (variabel bebas), serta jawaban atas kepuasan sebagai akibat (pengaruh) dari kualitas pelayanan yang telah diterimanya, dan merupakan variabel terikat. Responden secara incidental sampling sebanyak 40 orang diberikan kuesioner, yang dikembalikan dan benar sejumlah 39 buah. Perhitungan uji kecukupan data menggunakan rumus Bernoulli:

$$
\mathrm{n} \geq \frac{(z \propto / 2)^{\wedge} 2}{\mathrm{e}^{\wedge} 2} \cdot p \cdot q
$$

dengan tingkat kepercayaan 95\% dan tingkat kesalahan 5\% akan diperoleh $\mathrm{z}_{\alpha / 2}=1,96$, sehingga $p$ (proporsi kuesioner yg benar) $=39 / 40=97,5 \%$ dan $\mathrm{q}$ (proporsi kuesioner yg salah) $=1 / 40=2,5 \%$ sehingga $\mathrm{n}$ dihitung sebagai berikut:

$$
\mathrm{n} \geq \frac{(1,96) 2}{(0,05)^{2}} \cdot(97,5 \%) \cdot(2,5 \%)
$$

jadi $\mathrm{n} \geq 37,5$ sehingga kuesioner sudah mencukupi. Hasil uji validitas dan reliabilitas instrumen, dengan bantuan software SPSS 20, diperoleh ringkasan hasil sebagai berikut: 
Tabel 4. Ringkasan uji reliabilitas

\begin{tabular}{ccc}
\hline Variabel & $\begin{array}{c}\text { Alpha } \\
\text { Cronbach }\end{array}$ & Reliabilitas \\
\hline Kualitas pelayanan & 0,908 & Reliabel \\
Kepuasan pelanggan & 0,808 & Reliabel \\
\hline
\end{tabular}

Dari hasil uji reliabilitas diatas, berdasarkan koefisien Alpha Cronbach, semua item pertanyaan variabel hasilnya reliabel.

Tabel 5. Ringkasan uji validitas

\begin{tabular}{llllll}
\hline var & hasil & var & hasil & var & hasil \\
\hline X01 & valid & X10 & valid & X19 & valid \\
X02 & valid & X11 & valid & X20 & valid \\
X03 & valid & X12 & valid & X21 & valid \\
X04 & valid & X13 & valid & X22 & valid \\
X05 & valid & X14 & valid & X23 & valid \\
X06 & valid & X15 & valid & X24 & valid \\
X07 & valid & X16 & valid & X25 & valid \\
X08 & valid & X17 & valid & & \\
X09 & valid & X18 & valid & & \\
\hline
\end{tabular}

Dari hasil uji validitas diatas, berdasarkan koefisien Pearson Prodcut Moment, semua item pertanyaan variabel hasilnya valid.

\section{B. Kinerja Kualitas Pelayanan}

Kinerja kualitas pelayanan JM Motor terdiri atas unsur kehandalan (reliability), kepekaan (responsiveness), jaminan (assurance), empati (empathy), dan fisik (tangible), serta kepuasan yang diterima pelanggan JM Motor diperoleh dari kuesioner. Untuk membandingkan apakah tanggapan atas kualitas pelayanan yang diterima sudah sesuai dengan harapan pelanggan, dilihat gap (selisih nilai tingkat harapan dengan nilai tingkat kualitas pelayanan yang diterima) atau tingkat kesesuaian (nilai persentase perbandingan tingkat yang diterima dengan tingkat harapan).

Nilai gap positif berarti nilai kualitas pelayanan yang diterima (kinerja) belum memenuhi nilai harapan (belum memuaskan). Sebaliknya nilai gap negatif berarti kualitas pelayanan yang diterima sudah memenuhi harapan pelanggan (memuaskan). Pembandingan dilakukan dengan melihat persentase kualitas pelayanan yang diterima dengan yang diharapkan. Nilai persentase $>100 \%$ berarti nilai kualitas pelayanan yang diterima sudah memenuhi nilai harapan (memuaskan). Sebaliknya nilai persentase $<100 \%$ berarti kualitas pelayanan yang diterima belum memenuhi harapan pelanggan (belum memuaskan). Penilaian gap ini dapat dilihat pada tabel 6. di bawah ini.

Tabel 6. Tingkat kinerja pelayanan, tingkat kepentingan (harapan) dan tingkat kepuasan kualitas pelayanan JM Motor

\begin{tabular}{lccccc}
\hline No & $\begin{array}{c}\text { Variabel } \\
\text { kualitas pelayanan }\end{array}$ & $\begin{array}{c}\text { Skor } \\
\text { tingkat } \\
\text { yg } \\
\text { diterima } \\
\text { (kinerja) }\end{array}$ & $\begin{array}{c}\text { Skor tingkat } \\
\text { kepentingan } \\
\text { (harapan) }\end{array}$ & $\begin{array}{c}\text { Gap } \\
\text { (tingkat } \\
\text { harapan- } \\
\text { kinerja) }\end{array}$ & $\begin{array}{c}\text { Tingkat } \\
\text { kesesuaian }= \\
\text { Tk Yg ditrima/ } \\
\text { Tk harapan }\end{array}$ \\
\hline 1 & $\begin{array}{c}\text { Kehandalan } \\
\text { (reliabilitas) }\end{array}$ & 3,52 & 3,75 & 0,23 & 0,939 \\
\hline & $\begin{array}{c}\text { Kepekaan } \\
\text { (responsiveness) }\end{array}$ & 3,53 & 3,75 & 0,22 & 0,941 \\
\hline
\end{tabular}




\begin{tabular}{|c|c|c|c|c|c|}
\hline 3 & $\begin{array}{l}\text { Jaminan } \\
\text { (assurance) }\end{array}$ & 3,82 & 3,91 & 0,09 & 0,977 \\
\hline 4 & Empati (empathy) & 3,40 & 3,56 & 0,16 & 0,955 \\
\hline \multirow[t]{2}{*}{5} & Fisik (tangible) & 3,17 & 3,72 & 0,55 & 0,852 \\
\hline & Rata-rata total & 3,49 & 3,74 & 0,25 & 0,933 \\
\hline
\end{tabular}

Dari tabel 6. diatas, terlihat bahwa rata-rata (secara umum) skor tingkat kualitas pelayanan yg diterima sebesar 3,49 dan tingkat harapan 3,74 atau tingkat kinerja kualitas pelayanan lebih rendah dari tingkat harapan pelanggan. Dalam kondisi demikian, maka sesuai dengan pendapat Zeithaml, dkk. berarti kualitas pelayanan bengkel JM Motor belum memuaskan. Namun tidak terlalu jauh gapnya untuk masing-masing dimensi. Tetapi untuk aspek/dimensi fisik (tangible) selisihnya cukup signifikan, jadi cukup banyak perbedaan harapan dengan kinerja. Dimensi jaminan (assurance) memiliki selisih yang cukup sedikit $(0,09)$. Atau harapan pelanggan hampir terpuaskan oleh kinerja aspek jaminan. Oleh sebab itu fihak manajemen bengkel JM motor harus lebih meningkatkan lagi dimensi fisik (tangible). Gap masing-masing dimensi sbb:

a. Kehandalan (Reliabilitas), gap bernilai positif, berarti dibawah tingkat yang diharapkan. Kondisi ini menunjukkan bahwa dimensi kehandalan belum baik, belum memenuhi keinginan pelanggan dan perlu ditingkatkan.

b. Kepekaan (Responsiveness), gap bernilai positif, berarti dibawah tingkat yang diharapkan. Kondisi ini menunjukkan bahwa dimensi kepekaan belum memenuhi keinginan pelanggan dan perlu ditingkatkan.

c. Jaminan (Assurance), gap bernilai positif (relative kecil), berarti dibawah tingkat yang diharapkan. Kondisi ini menunjukkan bahwa dimensi jaminan belum memenuhi keinginan pelanggan dan perlu ditingkatkan.

d. Empati (Empathy), gap bernilai positif, berarti dibawah tingkat yang diharapkan. Kondisi ini menunjukkan bahwa dimensi kehandalan belum memenuhi keinginan pelanggan dan perlu ditingkatkan.

e. Bukti fisik (Tangibel) gap bernilai positif terbesar, berarti dibawah tingkat yang diharapkan. Kondisi ini menunjukkan bahwa dimensi bukti fisik belum memenuhi keinginan pelanggan dan harus ditingkatkan.

\section{Analisis Pengaruh Kualitas Pelayanan terhadap Kepuasan Pelanggan}

Dalam penelitian ini, kinerja kualitas pelayanan di bengkel JM motor dilihat pengaruhnya terhadap kepuasan pelanggan dengan menggunakan model regresi linier. Model regresi linier digunakan dengan asumsi bahwa data berdistribusi normal. Hipotesis yang disusun adalah:

Ho: tidak ada pengaruh kualitas pelayanan terhadap kepuasan pelanggan di bengkel JM motor

H1: ada pengaruh kualitas pelayanan terhadap kepuasan pelanggan di bengkel JM motor.

Dengan bantuan software SPSS 20 dan tingkat error $(\alpha=5 \%)$ diperoleh hasil sebagai berikut:

Tabel 7. Perhitungan regresi linier Model Summary

\begin{tabular}{|l|l|l|l|l|l|}
\hline Model & $\mathrm{R}$ & R Square & $\begin{array}{l}\text { Adjusted R } \\
\text { Square }\end{array}$ & $\begin{array}{l}\text { Std. Error of } \\
\text { the Estimate }\end{array}$ & $\begin{array}{l}\text { Durbin- } \\
\text { Watson }\end{array}$ \\
\hline 1 & $.586^{\mathrm{a}}$ & .344 & .326 & 1.740 & 1.382 \\
\hline
\end{tabular}

a. Predictors: (Constant), KP

b. Dependent Variable: KEP 
Interpretasi dari hasil diatas adalah:

1) Koefisien determinasi $\left(R^{2}\right)=0,326$ atau $32.6 \%$ menunjukkan bahwa variabel kepuasan pelanggan ditentukan $32.6 \%$ nya oleh variabel kualitas pelayanan. Sedangkan sisanya 67.4.\% ditentukan oleh variabel lain yang tidak diteliti.

2) Hasil uji t dan uji F menunjukkan:

ANOVA ${ }^{\mathrm{a}}$

\begin{tabular}{|l|l|l|c|r|c|c|}
\hline \multicolumn{2}{|l|}{ Model } & $\begin{array}{c}\text { Sum of } \\
\text { Squares }\end{array}$ & df & $\begin{array}{c}\text { Mean } \\
\text { Square }\end{array}$ & F & Sig. \\
\hline \multirow{3}{*}{1} & Regression & 58.709 & 1 & 58.709 & 19.385 & $.000^{\mathrm{b}}$ \\
\cline { 2 - 8 } & Residual & 112.060 & 37 & 3.029 & & \\
\cline { 2 - 7 } & Total & 170.769 & 38 & & & \\
\hline
\end{tabular}

a. Dependent Variable: KEP

b. Predictors: (Constant), KP

Coefficients ${ }^{\mathrm{a}}$

\begin{tabular}{|c|c|c|c|c|c|}
\hline \multirow[t]{2}{*}{ Model } & $\begin{array}{r}\text { Unstand } \\
\text { Coeffic } \\
\end{array}$ & $\begin{array}{l}\text { dardized } \\
\text { cients }\end{array}$ & $\begin{array}{r}\text { Standardized } \\
\text { Coefficients } \\
\end{array}$ & \multirow[t]{2}{*}{$\mathrm{t}$} & \multirow[t]{2}{*}{ Sig. } \\
\hline & \begin{tabular}{|l|}
$\mathrm{B}$ \\
\end{tabular} & Std. Error & Beta & & \\
\hline (Constant) & 3.482 & 2.388 & & 1.458 & .153 \\
\hline $\mathrm{KP}$ & .143 & .033 & .58 & 4.403 & .000 \\
\hline
\end{tabular}

a. Dependent Variable: KEP

3) $t_{\text {hitung(1.458) }}>t$ tabel(1.303) (untuk konstanta persamaan linier) dan $t$ hitung(4.403) $>t$ tabel(0.000) (untuk variabel kualitas pelayanan). Hasil $\mathrm{F}_{\text {hitung(19.385) }}>\mathrm{F}_{\text {tabel(4.10) }}$ dengan signifikansi $5 \%$, berarti bahwa variabel kualitas pelayanan secara signifikan mempengaruhi variabel kepuasan pelanggan.

4) Bentuk persamaan regresi linier dalam hal ini adalah $\mathrm{Y}=3.482+0,143 \mathrm{X}$ atau KEP $=$ $3.482+0,143 \mathrm{KP}$, dimana KEP $=$ kepuasan pelanggan bengkel $\mathrm{JM}$ Motor dan $\mathrm{KP}=$ kualitas pelayanan bengkel JM motor.

5) Hasil pengujian terhadap model regresi linier terdiri dari uji multikolineritas, uji otokorelasi, uji heterodaskisitas dan uji normalitas menggunakan SPSS 20 diperoleh hasil tidak terdapat multikolinieritas, tidak ada otokorelasi dan tidak ada heteroskedaskisitas serta berdistribusi normal. Jadi persmaan regresi linier yang terbentuk tepat. Hasil lengkapnya sebagai berikut:

hasil uji multikolineritas

\begin{tabular}{|c|c|c|c|c|c|c|c|}
\hline \multicolumn{8}{|l|}{ Coefficients $^{\mathrm{a}}$} \\
\hline \multirow[t]{2}{*}{ Model } & \multicolumn{2}{|c|}{$\begin{array}{l}\text { Unstandardized } \\
\text { Coefficients }\end{array}$} & $\begin{array}{r}\text { Standardized } \\
\text { Coefficients } \\
\end{array}$ & \multirow[t]{2}{*}{$\mathrm{t}$} & \multirow[t]{2}{*}{ Sig. } & \multicolumn{2}{|c|}{$\begin{array}{c}\text { Collinearity } \\
\text { Statistics }\end{array}$} \\
\hline & B & Std. Error & Beta & & & Tolerance & VIF \\
\hline Constant & 3.482 & 2.388 & & 1.458 & .153 & & \\
\hline$1 \longdiv { K P }$ & .143 & .033 & .586 & 4.403 & .000 & 1.000 & 1.000 \\
\hline
\end{tabular}

a. Dependent Variable: KEP

Coefficient Correlations ${ }^{\mathrm{a}}$

\begin{tabular}{|l|l|l|r|}
\hline \multicolumn{2}{|c|}{ Model } & \multicolumn{1}{c|}{ KP } \\
\hline \multirow{2}{*}{1} & Correlations & KP & 1.000 \\
\cline { 2 - 4 } & Covariances & KP & .001 \\
\hline
\end{tabular}

a. Dependent Variable: KEP 
Collinearity Diagnostics ${ }^{\mathrm{a}}$

\begin{tabular}{|r|c|c|c|c|c|}
\hline \multirow{2}{*}{ Model } & Dimension & Eigenvalue & \multirow{2}{*}{$\begin{array}{l}\text { Condition } \\
\text { Index }\end{array}$} & \multicolumn{2}{|c|}{ Variance Proportions } \\
\cline { 4 - 6 } & & & (Constant) & KP \\
\hline \multirow{2}{*}{1} & 1 & 1.993 & 1.000 & .00 & .00 \\
\cline { 3 - 6 } & 2 & .007 & 17.078 & 1.00 & 1.00 \\
\hline
\end{tabular}

a. Dependent Variable: KEP

Nilai signifikansi konstanta dan variabel kualitas pelayanan signifikan. Nilai tolerance $=$ $1,00>0,10$ dan VIF $=1,00<10$, artinya tidak ada multikolinieritas (Ghazali, 2011).

hasil uji otokorelasi

Collinearity Diagnostics ${ }^{\mathrm{a}}$

\begin{tabular}{|c|l|l|l|l|l|}
\hline Model & $\mathrm{R}$ & $\mathrm{R}$ & $\begin{array}{l}\text { Adjusted } \\
\text { R Square }\end{array}$ & & \multicolumn{2}{|l|}{ Variance Proportions } \\
\cline { 5 - 6 } & & Square & $\begin{array}{l}\text { Std.Error } \\
\text { Estimate }\end{array}$ & $\begin{array}{l}\text { Durbin- } \\
\text { Watson }\end{array}$ \\
\hline 1 & $0.586^{\mathrm{a}}$ & .344 & .326 & 1.740 & 1.382 \\
\hline
\end{tabular}

a.

redictors: (Constant), KP

b.

ependent Variable: KEP

Nilai koefisien Durbin Watson hitung $(\mathrm{dW}) 1,382$ dan nilai tabel $(\alpha=5 \%) \mathrm{dl}=1,382$ dan $\mathrm{du}=1,597$. Maka $\mathrm{dl}<=\mathrm{dW}(1.382)<=\mathrm{du}(2.388)$, artinya tidak ada autokorelasi positif (Ghazali, 2011).

hasil uji heteroskedaskisitas

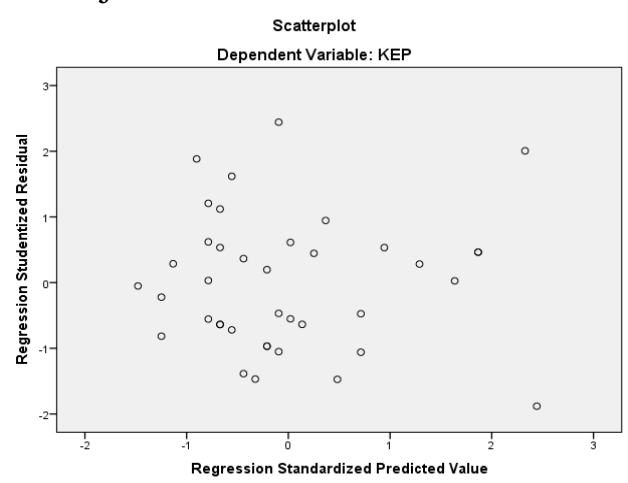

Sebaran titik-titik plot menunjukkan pola menyebar di sebelah kanan dan kiri skala nol vertikal, tidak terdapat pola tertentu. Jadi tidak terdapat heteroskedastisitas.

Hasil uji normalitas

\begin{tabular}{|l|r|l|l|l|l|l|l|r|r|r|}
\hline & \multicolumn{1}{|c|}{$\mathrm{N}$} & Minimum & Maximum & \multicolumn{1}{|c|}{ Mean } & \multicolumn{1}{|c|}{ Std. Deviation } & \multicolumn{2}{|c|}{ Skewness } & \multicolumn{2}{|c|}{ Kurtosis } \\
\cline { 2 - 9 } & Statistic & Statistic & Statistic & Statistic & \multicolumn{1}{c|}{ Statistic } & Statistic & Std. Error & Statistic & Std. Error \\
\hline Unstandardized Residual & 39 & -2.95983 & 4.19457 & OE-7 & 1.71724929 & .450 & .378 & -.214 & .741 \\
Valid N (listwise) & 39 & & & & & & & & \\
\hline
\end{tabular}

Nilai Zskewness $=$ skewness $/ \sqrt{ } 6 / \mathrm{n}$

$=0,450 / \sqrt{ } 6 / 39=1,147<1,96(\mathrm{Z} \%)$

Nilai Zkurtosis $=$ kurtosis $/ \sqrt{ } 24 / \mathrm{n}$

$=-0,214 / \sqrt{ } 24 / 39=-0,273<1,96(Z 5 \%)$

$\Rightarrow$ Distribusi normal (Ghazali, 2011). 


\section{Pembahasan dan Usaha Perbaikan}

Model persamaan $\mathrm{Y}=3,482+0,143 \mathrm{X}$ atau $\mathrm{KEP}=3,482+0,143 \mathrm{KP}$, dimana $\mathrm{KEP}=$ kepuasan pelanggan bengkel JM motor, $\mathrm{KP}=$ kualitas pelayanan bengkel JM motor, artinya:

1) Variabel kualitas pelayanan mempengaruhi ke-puasan pelanggan, dengan nilai tidak terlalu besar. Dari bentuk model persamaan linier, jika ada kenaikan kualitas pelayanan 1 (satu) satuan, akan memberikan dampak kenaikan kepuasan pelanggan sebesar 0,143 satuan. Sebaliknya jika terjadi penurunan kualitas pelayanan satu satuan, kepuasan pelanggan berkurang 0,143 satuan.

2) Dalam kasus kualitas pelayanan tidak ada, tetap memberikan dampak kepuasan pelanggan sebesar 3,482 satuan. Artinya pelanggan sudah merasa puas selama ini, namun penyebabnya disumbangkan oleh berbagai faktor lainnya selain kepuasan pelanggan.

Usaha-usaha yang bisa diimplementasikan berhubungan dengan penelitian di lapangan adalah bahwa kualitas pelayanan yang dinilai konsumen secara umum (semua dimensi) masih di bawah harapan. Jadi masih harus ditingkatkan terus-menerus karena akan memberikan dampak langsung terhadap kepuasan pelanggan, namun di sisi lain ada faktorfaktor lain yang mempengaruhi kepuasan pelanggan. Manajemen di bengkel JM motor harus selalu melakukan usaha-usaha yang dapat dilakukan dalam rangka memperbaiki kinerja kualitas pelayanan, dengan perbaikan pada semua aspek kualitas pelayanan:

a. kehandalan (reliability), dengan meningkatkan kehandalan (kompetensi kerja montir/mekanik), metode kerja dan kualitas fasilitas bengkel, peralatan bengkel (kuncikunci, kompresor dsb.), kelengkapan spareparts dan tata letak yang mendukung dalam proses pelayanan jasa bengkel.

b. kepekaan (responsiveness), dengan memperbaiki kepekaan pimpinan dan karyawan terhadap pelanggan, berupa layanan konsultasi, khususnya terutama pada saat pelanggan mengalami kesulitan atau hambatan sebelum, selama dan setelah memperbaiki/merawat motornya di bengkel JM motor.

c. jaminan (assurance), dengan meningkatkan lagi jaminan atas proses servis agar pelanggan merasa yakin atas proses servis di bengkel JM motor, jaminan atas kualitas dan kelengkapan spareparts, proses servis dan kemampuan pimpinan dan karyawan yang tepat dan sesuai dengan standar yang seharusnya (misalnya dengan mengikuti pelatihan/kursus), maupun memberikan jaminan (garansi) atas servis yang telah diberikan.

d. empati (empathy) dapat ditingkatkan lagi dengan memperbaiki sikap, perilaku para karyawan dan pimpinan terutama saat menangani pelanggan dengan kesulitan atau hambatan, misalnya pada saat memastikan jenis servis apa atau spareparts apa yang harus diganti, atau kesulitan-kesulitan lainnya. Bisa dilakukan dengan memberikan pelatihan personality dan customer service atau lainnya, sehingga dapat memberikan pelayanan pelanggan secara empatik.

e. fisik (tangible) dapat dilakukan dengan melakukan perbaikan dan melengkapi fasilitas fisik bengkel, memperbaiki kursi tunggu, peralatan yang sudah lama atau rusak, penataan rak tempat spareparts, informasi harga yang mudah diketahui dan mudah dijangkau pelanggan, membuat kondisi ruangan bengkel nyaman, dilengkapi dengan akses internet, toilet yang bersih dan melengkapi (mengadakan) peralatan yang belum ada (dibutuhkan) di bengkel.

Untuk faktor lain yang sangat mempengaruhi kepuasan pelanggan $(67,4 \%)$, pemilik JM Motor perlu memikirkan faktor-faktor lain apa saja yang bisa ditingkatkan, misalnya faktor harga, pilihan merk spareparts, servis panggilan (ke tempat pelanggan) dan sebagainya. 


\section{SIMPULAN}

Dari hasil pengolahan data dan analisis yang telah dilakukan ditarik kesimpulan sbb:

1. Tingkat kepuasan pelanggan bengkel JM Motor atas pelayanan yang diberikan selama ini menunjukkan rata-rata belum memuaskan, ditunjukkan dengan skor rata-rata kinerja 3,49 dan harapan 3,74. Skor tertinggi diberikan untuk dimensi jaminan (responsiveness) dengan skor 3,82 dan skor terendah untuk dimensi fisik (tangible) dengan skor 3,17. Dimensi fisik (tangibles) dan jaminan (assurance) harus segera diperbaiki (priorotas) oleh manajemen untuk ditingkatkan.

2. Kualitas pelayanan bengkel JM Motor memberikan pengaruh terhadap kepuasan pelanggan secara signifikan sebesar 32,6\% (pengaruhnya tidak terlalu kuat) dan $67,4 \%$ (kuat) oleh faktor lain. Persamaan regresi liniernya $\mathrm{Y}=3.482+0,143 \mathrm{X}$ atau $\mathrm{KEP}=3.482+0,143 \mathrm{KP}$, dimana $\mathrm{KEP}=$ kepuasan pelanggan bengkel JM Motor dan $\mathrm{KP}=$ kualitas pelayanan bengkel JM motor.

Tindak lanjut hasil penelitian ini, disarankan agar:

1. Selama ini pelanggan belum merasa puas, atau ada kesenjangan dengan harapan mereka. Untuk itu JM Motor harus melakukan perbaikan-perbaikan berbagai aspek (dimensi) kualitas pelayanan.

2. Kualitas pelayanan diperlukan untuk meningkatkan kepuasan pelayanan pelanggan, selain itu dalam jangka panjang untuk mengantisipasi persaingan dengan bengkel motor lain, agar bengkel JM Motor dapat tetap eksis dan maju. Evaluasi bisa dilakukan secara rutin/berulang.

3. Perlu dilakukan penelitian terkait dengan aspek lain yang cukup mempengaruhi kepuasan pelanggan bengkel untuk meningkatkan jumlah pelanggan bengkel JM Motor, mengingat $67,4 \%$ kepuasan disumbang oleh faktor lain, sehingga mendukung peningkatan keuntungan dan keberlanjutan usaha.

\section{DAFTAR PUSTAKA}

Aaker, D. A., Kumar, V., Day, George S., (2007). Marketing Research. New Jersey: John Wiley Int.

American Society for Quality. (2009). The Sertified Quality Engineer'a Handbook. Borror, C.M. editor,. Milwaukee: Quality Press.

BPS Bandung Barat. (2015). Bandung Barat Dalam Angka 2015. Bandung Barat: BPS Bdg Barat.

BPS Jawa Barat. (2015). Bandung Barat Dalam Angka 2014. Bandung: BPS Jawa Barat.

Bungin, Burhan. (2013). Metodologi Penelitian Sosial \& Ekonomi. Jakarta: Kencana Prenada Grup.

Cooper,D.R., Schindler,P. (2008). Business Research Methods, NewYork: Mc.Graw Hill Int' $1,10^{\text {th }}$ ed

Ghozali, Imam. (2011). Analisis Multivariate dgn Program IBM SPSS. 19. Semarang: BP Undip.

Kemenperin RI, (2015). Industry Facts and Figures 2015. Jakarta: Pusat Komunikasi Publik

Kotler, Philips and Keller, Kevin L. (2009). Marketing Management. New Jersey: Pearson Educ.

Kurniasari, Ardiana, dan Hadi Cholichul. (2012). Penilaian Kualitas Pelayanan Jasa oleh Konsumen Bengkel Resmi Sepeda Motor Honda AHASS UD. Ramayana Motor Surabaya. Jurnal Psikologi Industri dan Organisasi, Vol.1 No.02 , Juni 2012 Hal: 71-77.

LPPI dan Bank Indonesia. (2015). Profil Bisnis Usaha Mikro, Kecil dan Menengah (UMKM).

Lupiyoadi, Rambat. (2001), Manajemen Pemasaran Jasa, Jakarta: Salemba Empat.

Nasution, Arman H. (2006). Manajemen Industri. Yogyakarta: Penerbit Andi.

Nugraha, Rizal, (2014). Usulan Peningkatan Kualitas Pelayanan Jasa pada Bengkel "X"

Berdasarkan Hasil Matrix IPA (Studi Kasus di Bengkel AHASS PD. Sumber Motor Karawang). Jurnal Reka Integra. No.03 Vol.01 
Parasuraman, Zeithaml, Berry, (1988). A Multiple Item Scale for Measuring Consumer Perception of Service Quality, Journal of Retailing, Vol. 64 No. 1

Rangkuti, Freddy. (2002). Riset Pemasaran. Jakarta: Gramedia Pustaka Utama.

Schiffman, L.G. Kanuk, LL. (2007). Consumer Behavior, $9^{\text {th }}$ ed. New Jersey: Pearson Int'1 Edition.

Shahin, Samea. (2010). Developing the Models of Service Quality Gaps, As Critial Discussion, Journal of Business Management and Strategy, Vol 1 No. 1, 2010.

Sugiyono, (2009). Statistik untuk Penelitian, Bandung: Penerbit Alfabeta, cetakan ke-15.

Suharyanto, (2015). Kualitas Pelayanan, Antara yang Diterima dan Harapan Mahasiswa (Kasus Akper XYZ Bogor). Jurnal Ilmiah TEDC. Vol. 9. No. 1. Th. 2015. hal. 61-68.

Supranto, J., (2006). Pengukuran Tingkat Kepuasan Pelanggan untuk Menaikkan Pangsa Pasar. Jakarta: PT Rineka Cipta, cetakan ke-3.

Sutanto, Agus. (2011). Pengukuran Kualitas Jasa Bengkel Sepeda Motor SM di Kota Padang dgn Metode Servqual. Jurnal Optimasi Sistem Industri, Vol. 10 No. 2, Oktober 2011: 154159.

Syukri, Siti Husna Ainu. (2014) Penerapan CSI dan Analisis Gap pada Kualitas Pelayanan Trans Jogja. Jurnal Ilmiah Teknik Industri, Vol 13, No.2, hal 103-111.

Tahendrika, Abner. (2015). Analisis Kualitas Layanan Service Terhadap Tingkat Kepuasan Pengguna Motor Suzuki pada Bengkel PT Sinar Galesong Pratama Makassar. Jurnal Ekonomi, Manajemen dan Perbankan Vol 1 No 3: 85-99.

Tjiptono, Fandy. 2006. Riset Pemasaran dan Perilaku Konsumen, Jakarta: PT. Gramedia Pustaka

Zeithaml, Valarie, A., (2006). Services Marketing, Integrating Customer Focus Across the Firm, New York: Mc Graw Hill International, $4^{\text {th }}$ ed.

Zeithaml, Berry, Parasuraman, (1993). The Nature and Determinants of Customer Expectation of Services, Journal of Academy of Marketing Science, Vol-21 No1. 